\title{
Improvement of Power System Stability by Static Var Compensator and Tuning Employing Genetic Algorithm
}

\author{
Salma Keskes, Wissem Bahloul, Mohamed Ben Ali Kammoun \\ Commande des Machines Electriques et Reseaux de Puissance (CMERP), National Engineering School of Sfax, \\ Sfax, Tunisia \\ Email: salmakeskes@gmail.com
}

Received 28 May 2014; revised 26 June 2014; accepted 10 July 2014

Copyright (C) 2014 by authors and Scientific Research Publishing Inc.

This work is licensed under the Creative Commons Attribution International License (CC BY). http://creativecommons.org/licenses/by/4.0/

c) (i) Open Access

\section{Abstract}

The use of power systems as close to their operating limits can cause instability if a disturbance is occurred. The damping of the system's oscillations can be obtained by conventional means such as voltage and speed regulation but also by Flexible AC Transmission System devices (FACTS). These devices are increasingly used in power systems. This paper presents a systematic procedure for modelling and simulation of a single-machine infinite-bus power system installed with a Static VAR Compensator (SVC). So the impact of the SVC on power system stability can be reasonably evaluated. Genetic algorithm (GA) optimization technique is applied to design robust power system stabilizer and SVC-controllers for single-machine infinite-bus (SMIB) and is employed to search for optimal controller parameters.

\section{Keywords}

Genetic Algorithm, MATLAB/SIMULINK, Power System Stabilizer, SVC-Controller, SMIB, Transient Stability

\section{Introduction}

Over the past two decades, power system is being operated nearer to their stability limits due to the economic and environmental reasons.

The small signal stability of power systems, especially the damping of inter-area oscillations, has become, therefore a priority [1].

One of the main techniques employed to improve transient stability, and voltage regulation of generators con- 
sists of using power system stabilizer (PSS) that provides a maximum damping of electromechanical local modes.

Recently, there has been a surge of interest in the development and use of FACTS controllers in power transmission systems [2] [6] [11].

These controllers utilize power electronics devices to provide more flexibility to AC power systems. The most popular type of FACTS devices in terms of application is the SVC [4]. This device is well known to improve power system properties such as steady state stability limits, voltage regulation, and damp power system oscillations [3]. The SVC is an electronic generator that dynamically controls the flow of power through a variable reactive admittance to the transmission network.

In this paper, a systematic procedure for modeling, simulation and optimal tuning of PSS and SVC-controller in a SMIB power system was presented where the MATLAB/SIMULINK based model was developed and genetic algorithm (GA) was employed to design the PSS and SVC-based controller.

The design problem of PSS and SVC based controller to improve power system stability is transformed into an optimization problem. The design objective is to improve the stability of a SMIB power system by SVC and provide efficient damping of low frequency oscillations, subjected to a disturbance.

The merits of this study are summarized as follows:

In Section 2, the modeling of power system under study, which is a SMIB power system with a PSS and Static Var Compensator (SVC), is presented. The proposed controller structure is described in this section.

In Section 3, problem formulation and a short overview of GA are presented. In Section 4, we simulate the power system to illustrate the effectiveness of the proposed approach and the role of SVC to improve transient stability. Also, we compare the results with those obtained when the stability is ensured only with PSS summarizes the results. Section 5 draws the conclusion.

\section{System Modelling}

\subsection{Generator Model}

The power system is represented by a single-machine-infinite-bus (SMIB) shown in Figure 1.

The complete dynamic model of alternator is 7th order.

As this model is complicated, a validated third order dynamic generator model is adopted [3].

The power system can be modeled by a set of nonlinear differential equations are as follows:

$$
\left\{\begin{array}{l}
\dot{\delta}=\omega \\
\dot{\omega}=-\frac{D}{H} \omega+\frac{\omega_{S}}{H}\left(P_{m}-P_{e}\right), \\
\dot{E}_{q}^{\prime}=\frac{1}{T_{d 0}^{\prime}}\left(E_{f}-E_{q}\right) \\
P_{e}(t)=\frac{V_{S} E_{q}}{x_{d s}} \sin \delta(t)
\end{array}\right.
$$

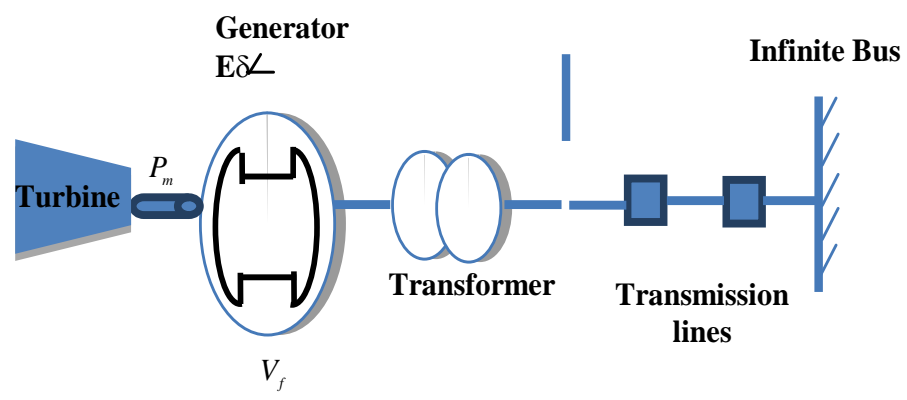

Figure 1. Single machine infinite bus. 


$$
\begin{gathered}
E_{q}(t)=\frac{x_{d s}}{x_{d s}^{\prime}} E_{q}^{\prime}(t)-\frac{x_{d}^{\prime}-x_{d}}{x_{d s}^{\prime}} V_{s} \cos \delta(t) \\
E_{f}(t)=k_{c} V_{f} \\
V_{t}=\frac{1}{x_{d s}} \sqrt{x_{s}^{2} E_{q}^{2}+V_{s}^{2} x_{d}^{2}+2 x_{s} x_{d} V_{s} E_{q} \cos \delta}
\end{gathered}
$$

where

$$
x_{\mathrm{s}}=x_{T}+x_{L}
$$

The generator is equipped with PSS (Power System Stabilizer) which are used in conjunction with Automatic Voltage Regulators (AVR) to damp out the oscillations.

\subsection{Structure of Power System Stabilizer}

The operating function of a PSS is to produce a proper torque on the rotor of the machine involved in such a way that the phase lag between the exciter input and the machine electrical torque is compensated. The supplementary stabilizing signal considered is one proportional to speed. The structure consists of a gain block with gain $K_{\text {Stab }}$, a signal washout block and stage phase compensation block as shown in Figure 2.

The input signal of the proposed controller is the speed deviation $(\Delta \omega)$, and the output is the stabilizing signal $V_{\mathrm{PSS}}$ which is added to the reference excitation system voltage. The signal washout block serves as a high-pass filter, with the time constant $T_{w}$, high enough to allow signals associated with oscillations in input signal to pass unchanged. From the viewpoint of the washout function, the value of $T_{w}$ is not critical and may be in the range of 1 to 20 seconds. The phase compensation block (time constants $T_{1}, T_{2}$ ) provides the appropriate phase-lead characteristics to compensate for the phase lag between input and the output signals.

The block diagram of the PSS with excitation system is shown in this figure.

\subsection{SVC Modeling and Damping Controller Design}

The SVC is a shunt FACTS and an important reactive compensation device. It is placed at the middle of the transmission line as shown in Figure 3.

SVC regulates the voltage at its terminals by controlling the amount of reactive power injected into, or absorbed from the power system.

When the system voltage is low, SVC generates reactive power (capacitive mode) and when the voltage is high, it absorbs reactive power (inductive mode).

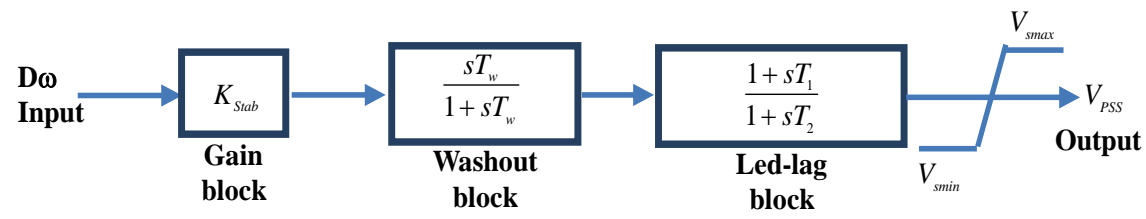

Figure 2. Bloc diagramm of PSS.

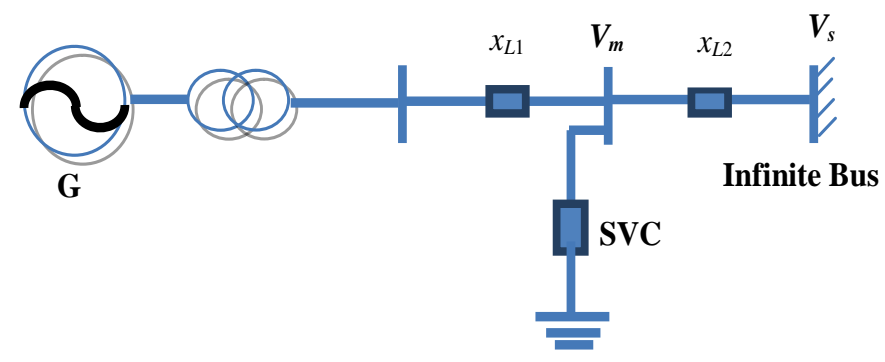

Figure 3. Structure of the SVC. 
Thus, the main benefit of the SVC for transient stability enhancement is direct and rapid bus voltage control.

The idea is to have an adjustable device impedance $\left(X_{\mathrm{SVC}}\right)$, it consists of Thyristor Switched Capacitor (TSC) and Thyristor Controlled Reactors (TCR) as shown in Figure 4 [5]-[9]. The SVC can be defined than, as a controlled susceptance (inverse of the impedance) called $B_{\mathrm{SVC}}$.

Where $V_{m}=$ SVC bus bar voltage, $X_{L}=L \omega$ is the fundamental-frequency reactance of the reactor, $\omega=2 \pi f, \alpha$ is the gating delay angle and $\sigma$ is the conduction angle: $\sigma=2(\pi-\alpha)$.

The fundamental component of the instantaneous current $i_{\mathrm{TCR}}(t)$ is given by is found by Fourier analysis:

$$
I_{\mathrm{TCR}}=V_{m} \cdot B_{L}(\alpha)
$$

The relationship between the firing angle $\alpha$ and the steady state value of $B_{\mathrm{TCR}}$ is given as follows:

$$
B_{L}(\alpha)=\frac{2(\pi-\alpha)+\sin (2 \alpha)}{\pi X_{L}} ; \quad \frac{\pi}{2} \leq \alpha \leq \pi
$$

The equivalent susceptance of the SVC, $B_{\mathrm{SVC}}$, is given by

$$
B_{\mathrm{SVC}}(\alpha)=\frac{1}{X_{C}}-B_{L}(\alpha)
$$

The major role of static VAC compensator is adjusting the voltage at its terminals. SVS is usually modeled by the block diagram shown in Figure 5.

The main controller of the tension can be proportional, integral or a combination of both actions.

The SVC dynamic regulator can be written as follows:

$$
\dot{B}_{L}=\frac{1}{T_{\mathrm{SVC}}}\left(-B_{L}(t)+B_{L 0}+K_{\mathrm{SVC}} U_{B}(t)\right)
$$

where $B_{L}(t)$ is the susceptance of the inductor in SVC; $B_{L 0}$ is the initial susceptance of the TCR; $T_{\mathrm{SVC}}$ the time constant of the SVC regulator, $K_{\mathrm{SVC}}$ the gain of the SVC regulator and $U_{B}(t)$ is the input of the SVC regulator.

The mathematical model of SMIB system with SVC on the transmission line may be presented by the classic third order model as given by Equation (1) and the SVC model represented by the fourth one [10]:

$$
\left\{\begin{array}{l}
\dot{\delta}=\omega \\
\dot{\omega}=-\frac{D}{H} \omega+\frac{\omega_{S}}{H}\left(P_{m}-P_{e}\right) \\
\dot{E}_{q}^{\prime}=\frac{1}{T_{d 0}^{\prime}}\left(E_{f}-E_{q}\right) \\
\dot{B}_{L}=\frac{1}{T_{\mathrm{SVC}}}\left(-B_{L}(t)+B_{L 0}+K_{\mathrm{SVC}} U_{B}(t)\right)
\end{array}\right.
$$

The electric equations for the equation the SMIB-SVC are:

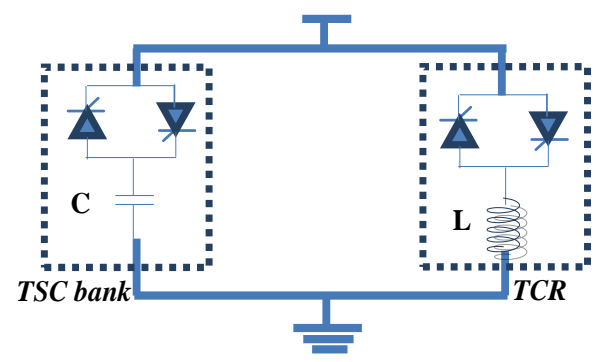

Figure 4. Single machine system with SVC. 


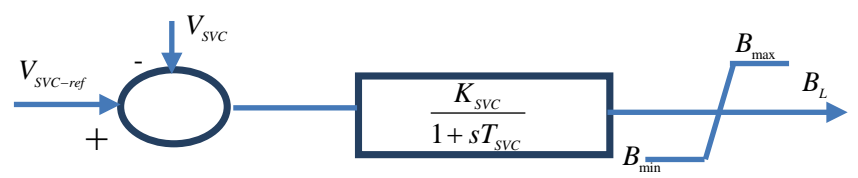

Figure 5. Block diagram of the SVC controller.

$$
\left\{\begin{array}{l}
V_{E}=\frac{V_{S}}{x_{L 2}\left(B_{L}(t)-B_{C}\right)+1}, \\
x_{E}=\frac{x_{L 2}}{x_{L 2}\left(B_{L}(t)-B_{C}\right)+1}, \\
x_{d s}^{\prime}=x_{T}+x_{d}^{\prime}+\left(x_{L 1}+x_{E}\right), \\
I_{d}=\frac{E_{q}^{\prime}-V_{E} \cos \delta}{x_{d s}^{\prime}}, \\
I_{q}=\frac{V_{E} \sin \delta}{x_{d s}^{\prime}}, \\
E_{q}=E_{q}^{\prime}+\left(x_{d}-x_{d}^{\prime}\right) I_{d}, \\
P_{e}=E_{q}^{\prime} I_{q},
\end{array}\right.
$$

\section{Problem Formulation}

In the present study, a washout time constant of $T_{w}=1.0 \mathrm{~s}$ is used.

The stabilizer gains $K_{\mathrm{SVC}}$ and $K_{\mathrm{PSS}}$, and time constants $T_{1}, T_{2}$ and $T_{\mathrm{SVC}}$ are remained to be determined.

The parameters of the PSS and SVC are optimized using integral of time multiplied absolute value of the error (ITAE) as objective function:

$$
J=\int_{0}^{t_{\text {sim }}} t \cdot|\Delta \omega| \cdot \mathrm{d} t
$$

where $\Delta \omega$ denotes the speed deviation of SMIB system generator $t_{\text {sim }}$ is the time range of the simulation.

Based on the objective function $J$ optimization problem can be stated as:

\section{Minimize $J$}

\section{subjected to:}

$$
\begin{aligned}
& T_{1}^{\min } \leq T_{1} \leq T_{1}^{\max } \\
& T_{2}^{\min } \leq T_{2} \leq T_{2}^{\max } \\
& T_{\mathrm{SVC}}^{\min } \leq T_{\mathrm{SVC}} \leq T_{\mathrm{SVC}}^{\max } \\
& T_{\mathrm{SVC}}^{\min } \leq T_{\mathrm{SVC}} \leq T_{\mathrm{SVC}}^{\max } \\
& K_{\mathrm{SVC}}^{\min } \leq K_{\mathrm{SVC}} \leq K_{\mathrm{SVC}}^{\max }
\end{aligned}
$$

\subsection{Overview of Genetic Algorithm (GA)}

The genetic algorithm (GA) has been used to solve difficult engineering problems that are complex and difficult to solve by conventional optimization methods. GA maintains and manipulates a population of solutions and implements a survival of the fittest strategy in their search for better solutions. The fittest individuals of any population tend to reproduce and survive to the next generation thus improving successive generations. The inferior individuals can also survive and reproduce.

Implementation of GA requires the determination of six fundamental issues: chromosome representation, selection function, the genetic operators, initialization, termination and evaluation function [7] [8]. The computational flowchart of the GA optimization process employed in the present study is given in Figure 6. 


\subsection{Application of Genetic Algorithm (GA)}

Table 1 shows the optimal values of PSS and SVC-controller parameters obtained by the GA for SMIB system.

\section{Simulation and Results}

This section illustrates the simulation of the mathematical model containing a simple transmission system containing single generator equipped with an excitation system and power system stabilizer (PSS) and connected to an infinite bus. The utility of placing the Static VAR Compensator (SVC) at transmission line of SMIB system is to improve transient stability and power oscillation damping of the system.

The transient stability improvement for the single-machine infinite-bus power system was thoroughly estimated from two types of defects.

To show the effectiveness of the proposed control scheme, we compare the performance of the power system under the proposed approach and the conventional PSS whose parameters are shown in Appendix.

\subsection{Increase of the Mechanical Input Power}

An alternator behavior simulation following a step change in the value of the mechanical power input is given. The simulation steps are organized as:

Step 1: The system is in pre-faulted steady state;

Step 2: A range of 0.2 p.u. pulse increase in the input mechanical power at $t_{0}=4 \mathrm{~s}$;

Step 3: The system is in a post fault state.

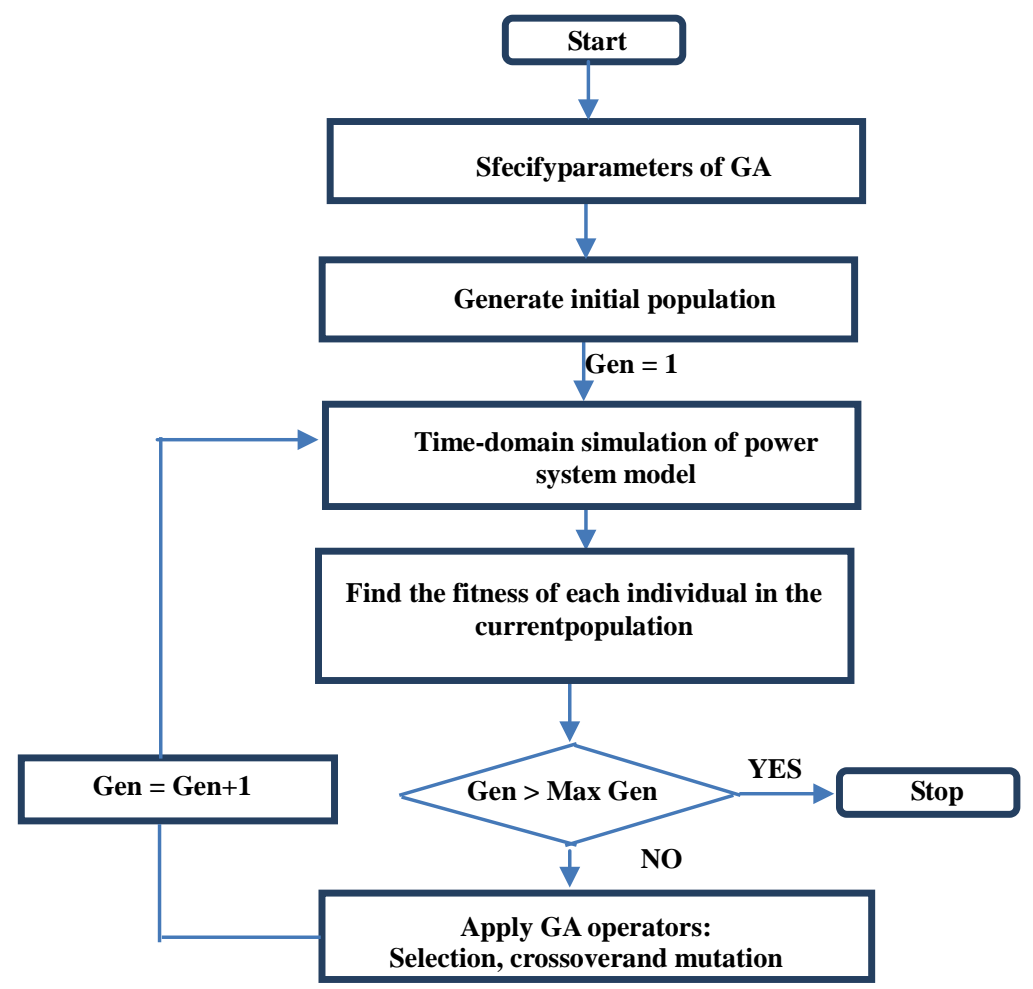

Figure 6. Flowchart of genetic algorithm.

Table 1. Optimized PSS and SVC-controller parametres for SMIB system.

\begin{tabular}{ccccc}
\hline$T_{1}$ & $T_{2}$ & $T_{\mathrm{svC}}$ & $K_{\mathrm{pss}}$ & $K_{\mathrm{svc}}$ \\
\hline $\mathbf{0 . 1 9 6 6}$ & $\mathbf{0 . 0 2 0 8}$ & $\mathbf{0 . 0 8 5 4}$ & $\mathbf{1 0}$ & $\mathbf{2 . 5 9} \times \mathbf{1 0}^{-\mathbf{4}}$ \\
\hline
\end{tabular}


The simulation results are shown in Figures 7-11.

\subsection{Three Phase Short Circuit}

The object of the second simulation is to verify the effect of a high amplitude perturbation.

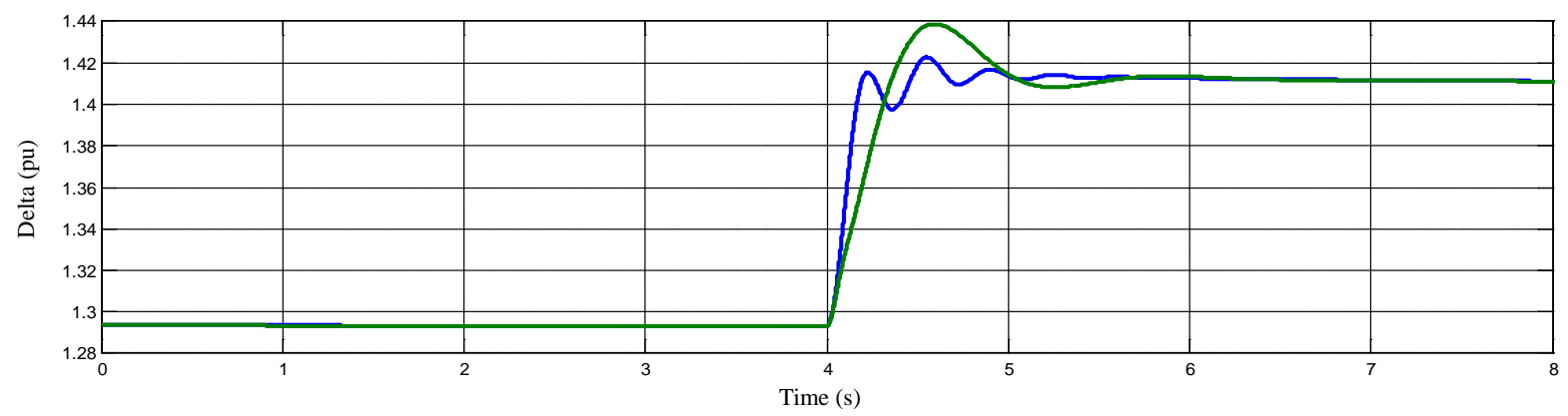

Figure 7. Transient responses of the power angle.

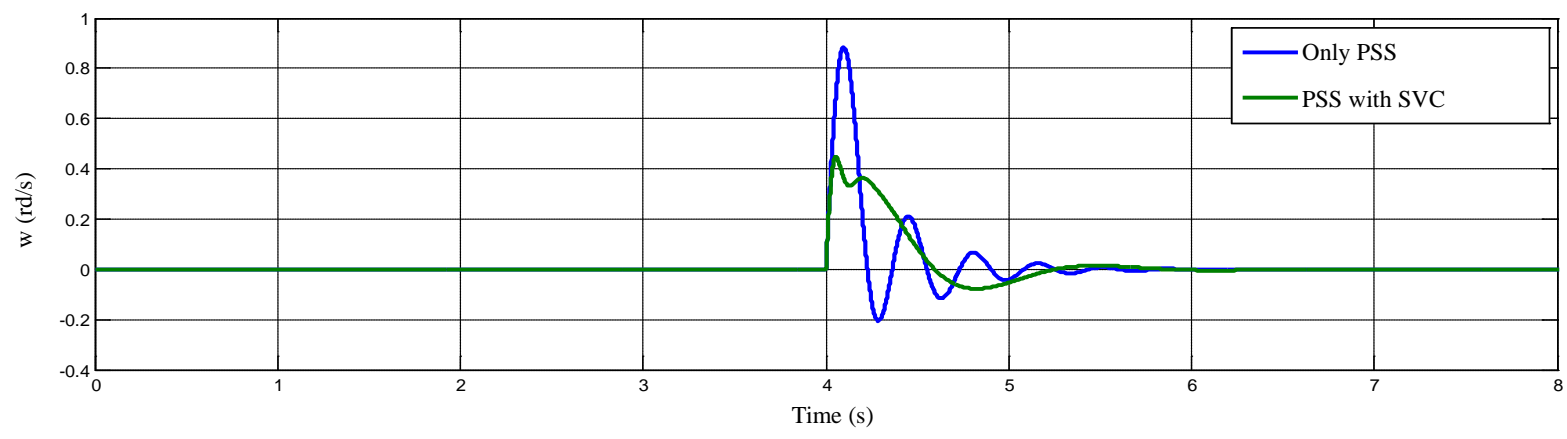

Figure 8. Speed variation of the generator.

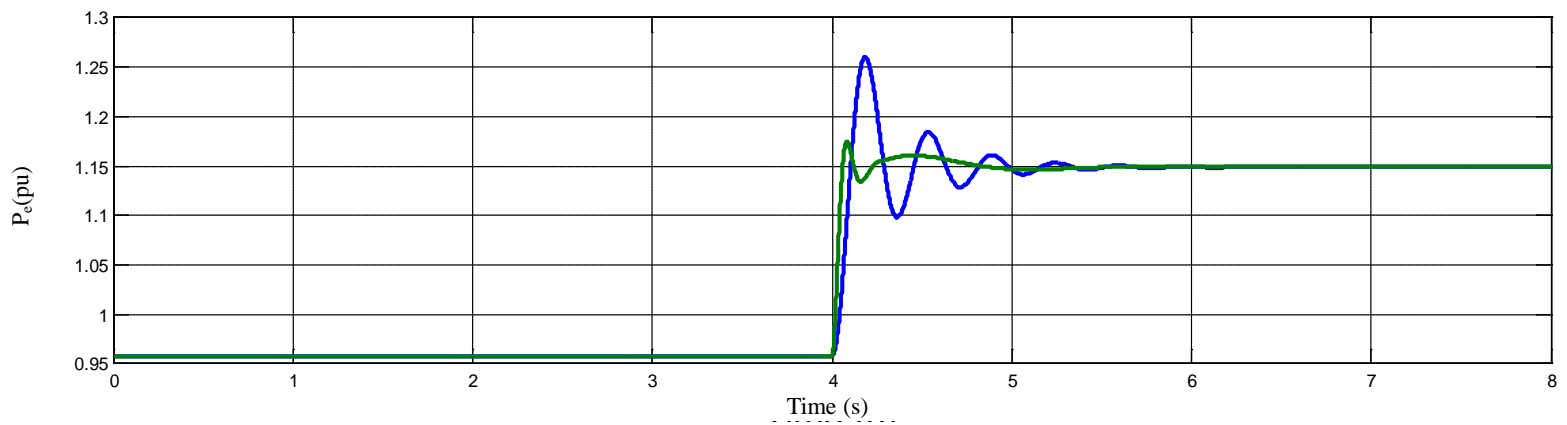

Figure 9. Evolution of the active power delivered by the generator.

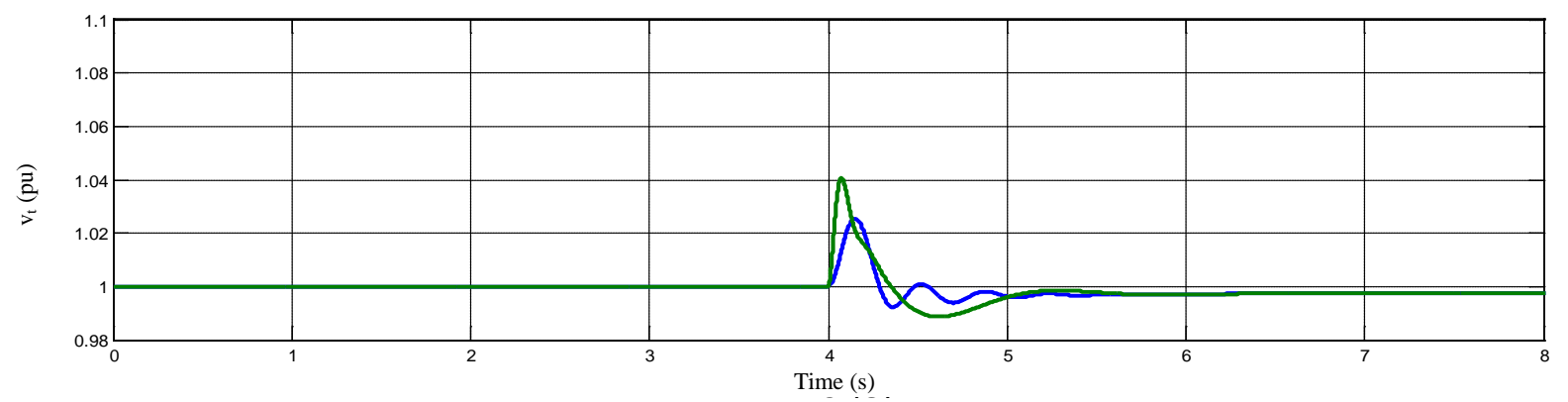

Figure 10. Evolution of the the terminal voltage of the MS Speed. 
The experiment consists of a three-phases short-circuit followed by the elimination of one transmission line. The simulation is performed according to the following sequences:

Step 1: The system is in pre-faulted steady state;

Step 2: A fault occurs at $t_{0}=15.2 \mathrm{~s}$;

Step 3: The fault is cleared after $t=0.07 \mathrm{~s}$ by opening the breaker of the faulted line;

Step 4: The system is in a post fault state.

The simulation results are shown in Figures 12-16.

All this figures show the responses of different parameters with and without SVC.

The results of these studies show that the SVC has an excellent capability in damping power system oscillations and enhances greatly the dynamic stability of the power system. We also note that the stabilization time is minimal.

\section{Conclusion}

Static VAR Compensation (SVC) is a relatively new way of transient stability improvement for Power System Stabilizer (PSS) equipped power systems. This paper aims, by the present system study, to take more advantage of this reactive compensation device.

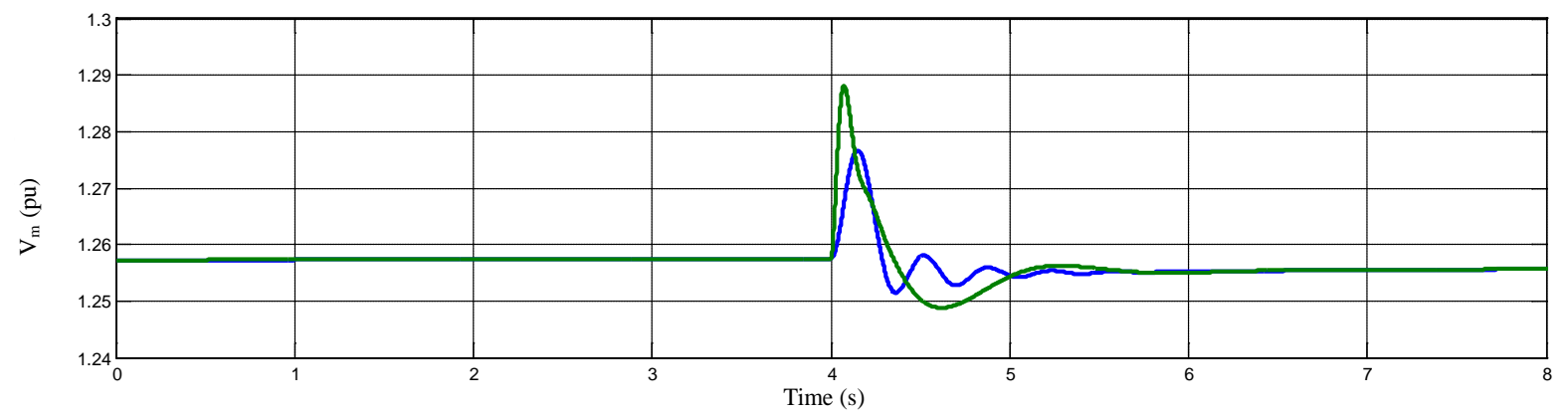

Figure 11. SVC voltage in p.u.

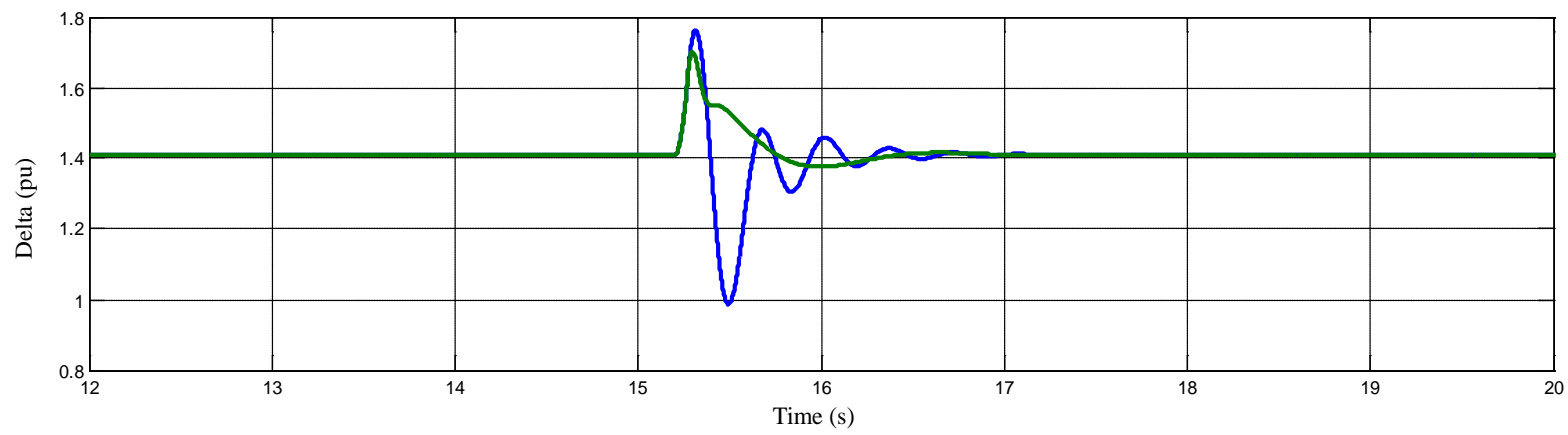

Figure 12. Transient responses of the power angle.

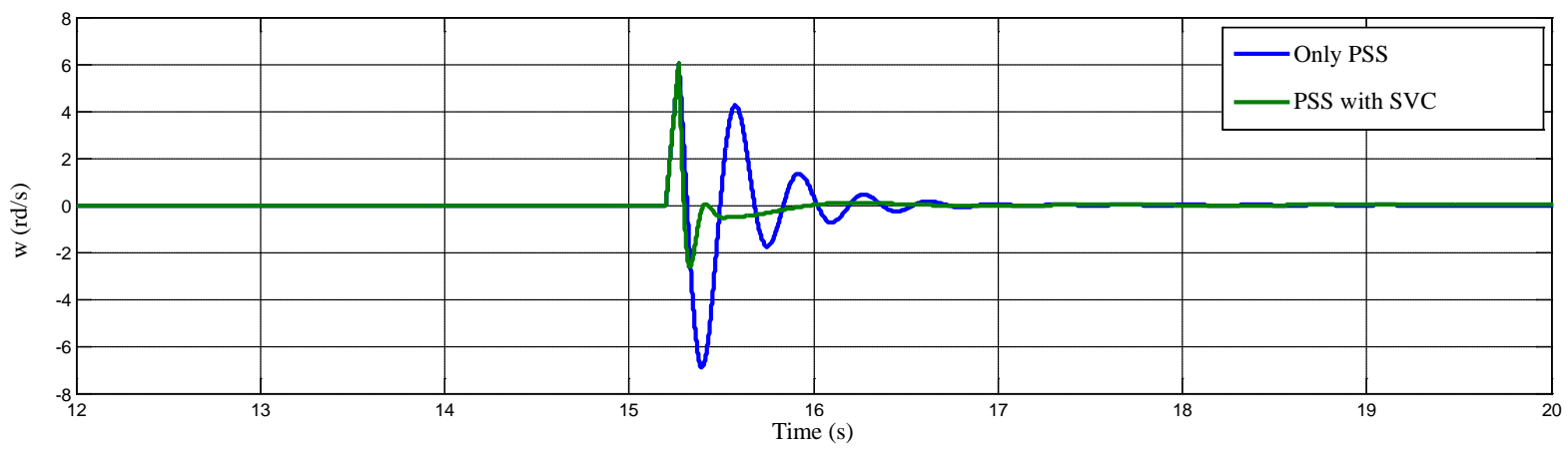

Figure 13. Speed variation of the generator. 


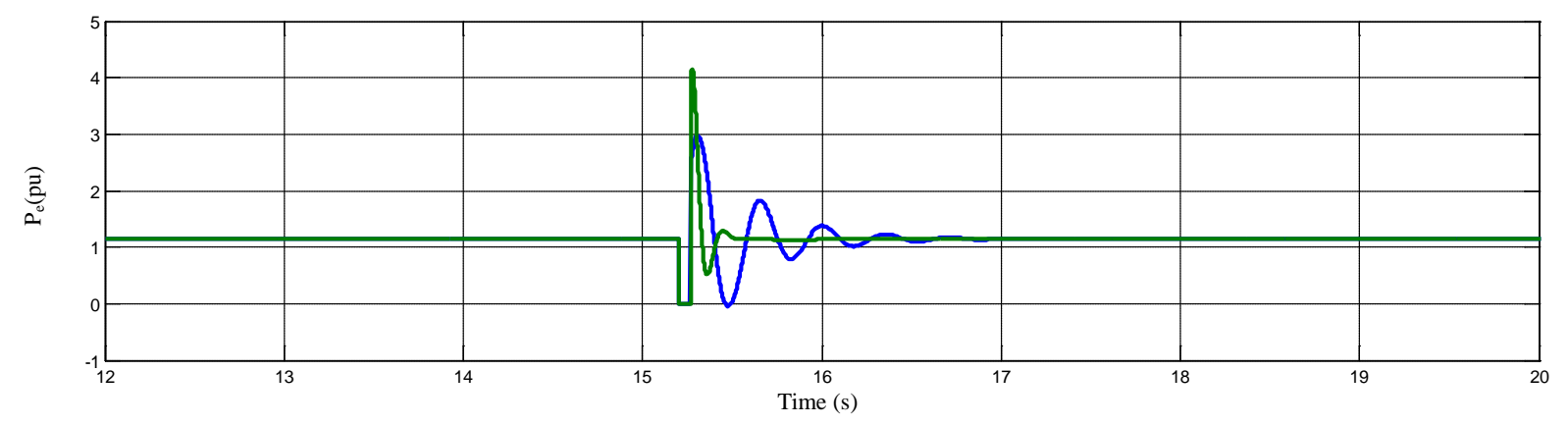

Figure 14. Evolution of the active power delivered by the generator.

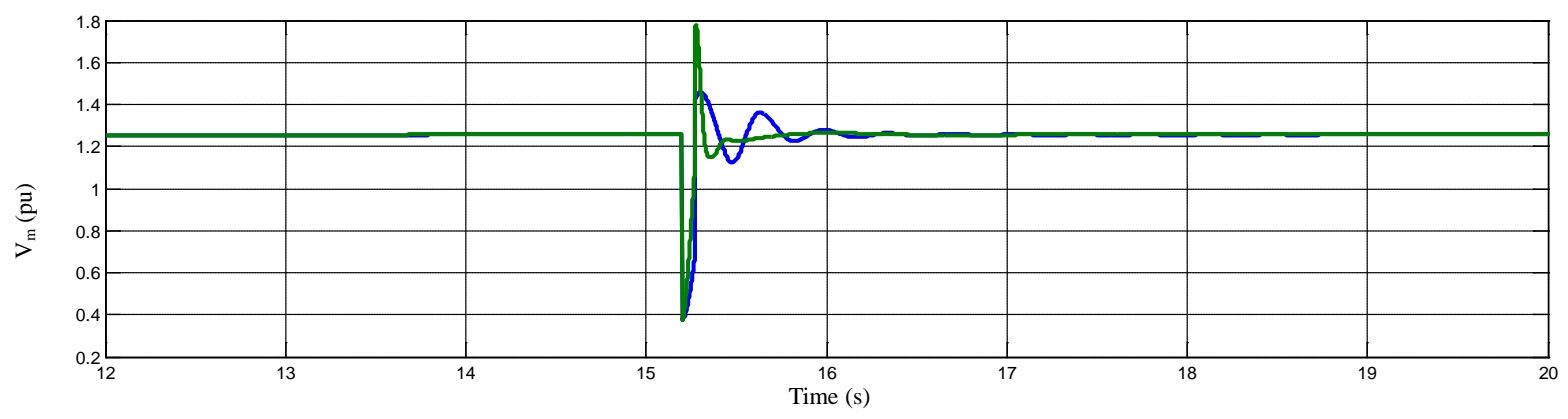

Figure 15. Evolution of the the terminal voltage of the MS speed.

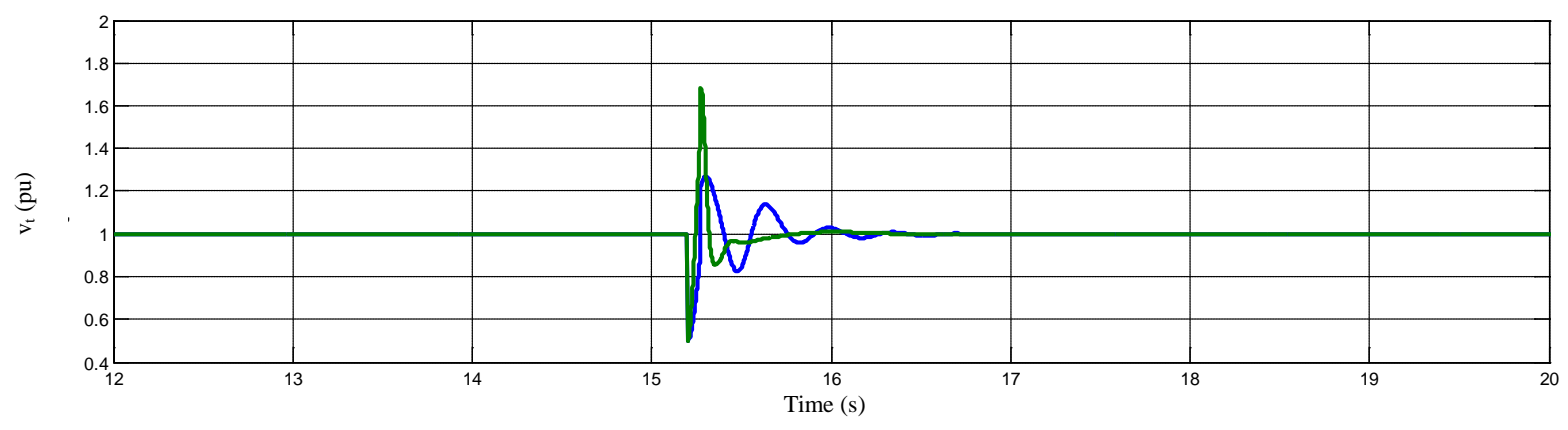

Figure 16. SVC voltage in p.u.

In this paper, a reduced from seventh to third order modelling of the studied power system was given. Steady modelling of the SVC explains the role of this last in power generation chain. A mathematical dynamic model was also presented in a first order transfer function form.

Simulation results show clearly improvement compared to systems using only PSS. In fact, improvement touches especially generator power angle and the terminal voltage of generator which have a critical part in the system stability.

Also the results show that genetic algorithm allows to have optimal controller parameters to ensure convergence in a short time.

\section{Acknowledgements}

Authors of this work would like to thank University of Sfax, Tunisia and especially the research unit CMERP for providing the facilities and research grant to achieve this research and great thanks to the reviewers for their valuable comments.

\section{References}

[1] Kundur, P., Paserba, J., Ajjarapu, V., Andersson, G., Bose, A., Canizares, C., Hatziargyriou, N., Hill, D., Stankovic, A., 
Taylor, C., Cutsem, T.V. and Vittal, V. (2004) Definition and Classification of Power System Stability. IEEE Transactions on Power Systems, 19, 87-140.

[2] Zakaria, M.H. (2012) Optimisation des paramètres d’un FACTS shunt pour l'amélioration de la stabilité transitoire d'un système électrique. SETIF University of Technology, Juin.

[3] Haimour, R. (2010) Contrôle des Puissances Réactives et des Tensions par les Dispositifs FACTS dans un Réseau Electrique. Ecole Normale Supérieure de l'Enseignement Technologique d’Oran, 2009. W. Bahloul, automatisation des essaies des machines électriques: Contribution à la modélisation, à l'identification et la commande d'une machine synchrone couplée au réseau. Theses ENIS Decembre 2010.

[4] Hingorani, N.G. and Gyugyi, L. (2000) Understanding FACTS: Concepts and Technology of Flexible AC Transmission Systems. IEEE Press, New York.

[5] Rios, M.A. (1992) Modélisation pour Analyses Dynamiques des Réseaux Electriques avec Compensateurs de Puissance Réactive-SVC. Grenoble, March.

[6] Panda, S. and Ardil, C. (2011) Real-Coded Genetic Algorithm for Robust Power System Stabilizer Design, World Academy of Science. Engineering and Technology International Journal of Electrical, Electronic Science and Engineering, 5, 66-74.

[7] Wang, Y.P., Hur, D.R., Chung, H.H., Watson, N.R., Arrillaga, J. and Matair, S.S. (2000) A Genetic Algorithms Approach to Design and Optimal PI Controller for Static VAr Compensator. International Conference on Power System Technology (PowerCon 2000), Christchurch, 4-7 December 2000, 1557-1562. http://dx.doi.org/10.1109/9.402235

[8] Acha, E., Fuerte-Esquivel, C., Ambriz-Perez, H. and Angeles-Camacho, C. (2004) FACTS Modelling and Simulation in Power Networks. John Wiley \& Sons LTD, England.

[9] Lei, X., Lerch, E. and Povh, D. (2001) Optimization and Coordination of Damping Controls for Improving System Dynamic Performance. IEEE Transactions on Power Systems, 16, 473-480. http://dx.doi.org/10.1109/59.932284

[10] Hingorani, N.G. and Gyugyi, L. (2001) Understanding FACTS. IEEE Press, Piscataway.

[11] Panda, S. and Padhy, N.P. (2007) Power System with PSS and FACTS Controller: Modelling, Simulation and Simultaneous Employing Genetic Algorithm. International Journal of Electrical and Electronics Engineering, 1, 9-18.

\section{Nomenclature}

\begin{tabular}{clll}
\hline$\omega:$ & Relative speed of the generator, in rad/s; & $x_{d s}:$ & Inductance of a stator phase; \\
& $x_{T}:$ & Reactance of the transformer; \\
$\delta:$ & Power angle of the generator, in rad; & $x_{d}^{\prime}:$ & Direct axis transient reactance of the generator; \\
$\omega_{s}:$ & Synchronous speed of the generator, in rad/s; & $x_{d s}^{\prime}:$ & Equivalent transient reactance observed by the generator, in p.u.; \\
$H:$ & Inertia constant, in s; & $x_{L}:$ & Line impedance; \\
$D:$ & Damping constant in p.u.; & $E_{f}: \quad$ The excitation voltage; \\
$V_{t}:$ & The generator terminal voltage; & $E_{q}^{\prime}:$ & q-Axis transient voltage, in p.u.; \\
$P_{m}:$ & Mechanical input power, in p.u.; & $V_{s}:$ & Infinite bus voltage in p.u.; \\
$P_{e}:$ & Active power delivered by the generator; & $T_{d 0}^{\prime}$ & Time constant of the excitation winding in s; \\
$x_{L i}:$ & Reactance of the transmission line, i=1,2, in p.u.; & $x_{d}:$ & Direct axis reactance of the generator. \\
\hline
\end{tabular}




\section{Appendix}

All data are in p.u. unless specified otherwise.

The parameters of the system are:

Generator parameters:

$$
\begin{aligned}
& V_{t}=1, f=50 \mathrm{~Hz}, x_{d}=1.863, x_{d}^{\prime}=0.25, x_{L 1}=0.24265, x_{L 2}=0.24265, \\
& x_{T}=0.2127, D=5, H=4, T_{d 0}^{\prime}=6.9, P_{m}=0.9575 .
\end{aligned}
$$

Initial condition:

$$
B_{L}=1, B_{C}=1, \delta_{0}=1.2553, E_{q 0}=2.1137, w_{0}=0 .
$$

Parameters used for the excitation system:

$$
K_{a}=200, T_{a}=0.15 \mathrm{~s}, k_{c}=1, V_{f}=2.257 .
$$

PSS parameters:

$$
K_{P S S}=9.5, T_{1}=0.154, T_{2}=0.154 .
$$

Network parameters:

$$
V_{s}=1 \text { p.u., } f=50 \mathrm{~Hz} \text {. }
$$


Scientific Research Publishing (SCIRP) is one of the largest Open Access journal publishers. It is currently publishing more than 200 open access, online, peer-reviewed journals covering a wide range of academic disciplines. SCIRP serves the worldwide academic communities and contributes to the progress and application of science with its publication.

Other selected journals from SCIRP are listed as below. Submit your manuscript to us via either submit@scirp.org or Online Submission Portal.
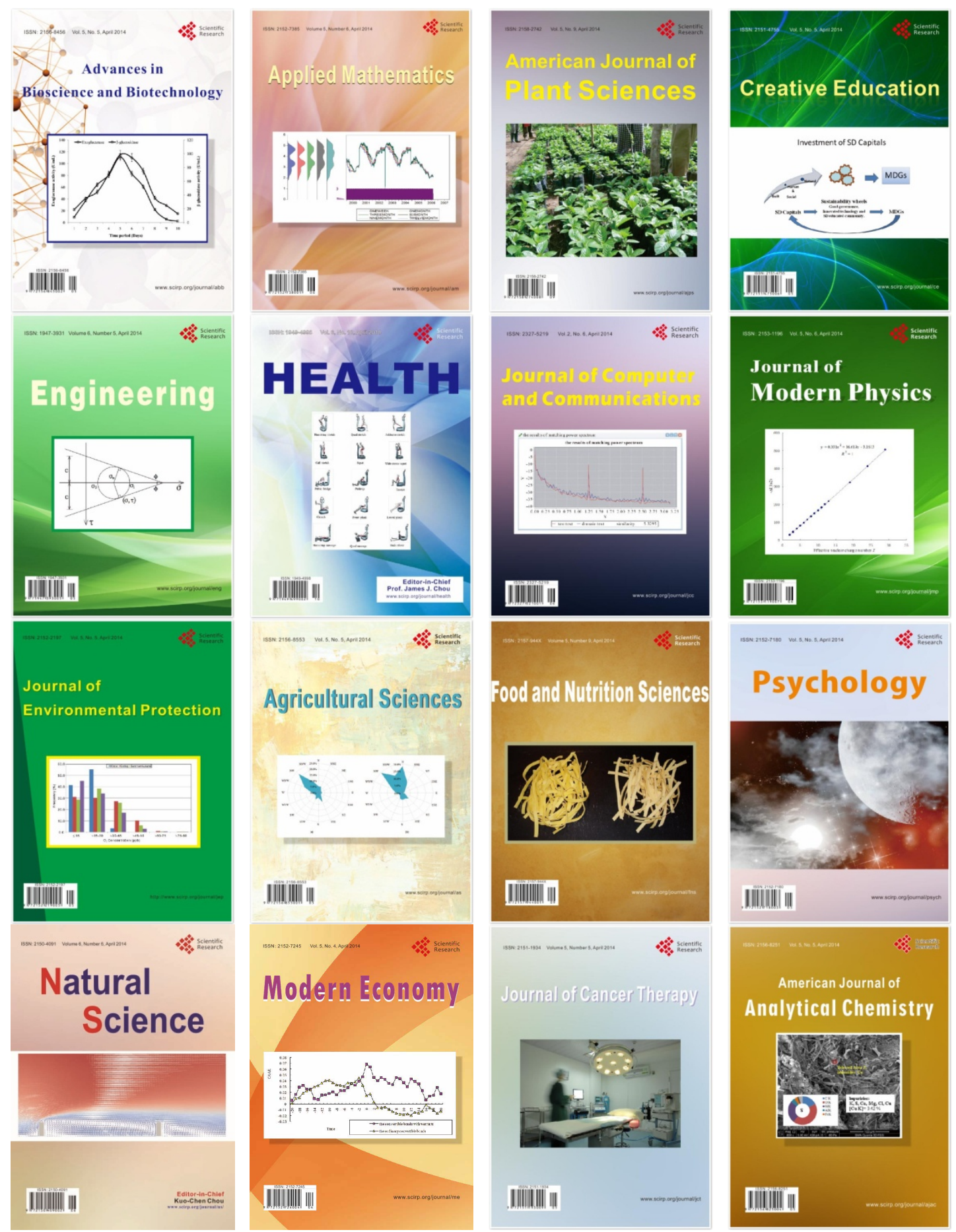